\title{
Psycho-emotional Consequences of Hospitalized Elder Abuse from Older Patients' Perspective
}

\author{
Zeinab Naderi ${ }^{1,2}$, Sakineh Gholamzadeh ${ }^{3^{*}}$, Ladan Zarshenas ${ }^{3}$, Abbas Ebadi ${ }^{4,5}$
}

\author{
${ }^{1}$ Student Research Committee, School of Nursing and Midwifery, Shiraz University of Medical Sciences, Shiraz, IRAN \\ ${ }^{2}$ Department of Nursing, Sirjan School of Medical Sciences, Sirjan, IRAN \\ ${ }^{3}$ Community Based Psychiatric Care Research Center, School of Nursing and Midwifery, Shiraz University of Medical Sciences, Shiraz, IRAN \\ ${ }^{4}$ Behavioral Sciences Research Center, Life Style Institute, Baqiyatallah University of Medical Sciences, Tehran, IRAN \\ ${ }^{5}$ Faculty of Nursing, Baqiyatallah University of Medical Sciences, Tehran, IRAN \\ *Corresponding Author: sakineh_gholamzadeh@yahoo.com
}

Citation: Naderi Z, Gholamzadeh S, Zarshenas L, Ebadi A. Psycho-emotional Consequences of Hospitalized Elder Abuse from Older Patients' Perspective. Electron J Gen Med. 2020;17(2):em194. https://doi.org/10.29333/ejgm/7811

\section{ARTICLE INFO}

Received: 12 Nov. 2019

Accepted: 26 Jan. 2020

\begin{abstract}
Introduction and Objective: The present study aimed to identify and describe psycho-emotional consequences of hospitalized elder abuse from older patients' views.
\end{abstract}

Methods: An inductive qualitative content analysis research was conducted at various wards of six educational hospitals affiliated to Shiraz University of Medical Sciences. A total of 16 elderly patients aged 60 years and older were selected using purposive sampling and data gathering was done using semi-structured, individual interviews. The data were analyzed using the qualitative content analysis method proposed by Elo and Kyngas (2008)

Results: The Psycho-emotional consequences of hospitalized elder abuse were reflected in three main categories, namely feeling of insecurity, aggression, and learned helplessness.

Conclusion: Hospitalized elder abuse could be accompanied with immediate Psycho-emotional consequences, such as feeling of insecurity and aggression, as well as persistent and long-term consequences, such as helplessness. Thus, monitoring and training the healthcare staff and raising their awareness regarding consequences of hospitalized elder abuse are necessary to prevent this phenomenon.

Keywords: elder abuse, elder neglect, hospitalization, patient outcome assessment, qualitative research

\section{INTRODUCTION}

Elder abuse is a major public health problem, which is accompanied with serious social, economic, and health consequences (1). It can occur in various settings, including individuals' houses, daily centers, hospitals, and nursing homes (2), and for all elderly people irrespective of sex, race, living arrangement, health status, and inability. Indeed, it can be committed by family members, hired caregivers, friends, neighbors, and healthcare providers including nurses (3). Elder abuse is classified into domestic and institutional categories (4).

Institutional elder abuse and abuse in healthcare settings are a part of violence in society $(5,6)$. In this context, elder abuse in institutions is one of the main concerns in taking care of elderly patients (7) and they are at risk of abuse in hospitals and clinical environments, and clinical practice $(2,3)$. Evidence has shown an alarming image of healthcare providers' unacceptable behaviors, including insensitivity and disrespect, towards elderly patients (8). Accordingly, care providers' burnout workload, individual and professional demands, job satisfaction rate, stressful work settings, weak education, patients' behavioral problems, and daily activities limitations, eventually leading to elder abuse (7). The prevalence of elder abuse in institutions might be higher than that reported in the literature because under-reporting of this phenomenon has been estimated to be around $80 \%$. Moreover, the total prevalence of elder abuse in institutions was $64.2 \%$ based on the staff's reports. Accordingly, two out of each three personnel had committed elder abuse during the past year (1).

Not only elder abuse has physical consequences, but it also exerts negative effects on individuals' mental health (9). Indeed, aging and its related diseases worsen the impacts of physical and psychological violence on older people's health (10). On the other hand, abuse in healthcare causes long-term suffering among patients, but the personnel have little knowledge in this respect (11). Such suffering is accompanied with negative consequences on patients' health and well-being as well as their future contacts with healthcare providers (12). Considering the consequences of abuse in the healthcare system, its ignorance would result in an ethical challenge for the system (13). In this regard, the patients who have experienced abuse in healthcare are considered to be a rich source of information (14) and using qualitative content analysis is quite appropriate for investigation of the characteristics of such a sensitive multifactorial phenomenon (15) and can help understand the consequences of hospitalized 
elder abuse and its latent components. Such studies would also enhance healthcare providers' awareness of outcomes of their abusive and negligent behaviors towards hospitalized elderly patients, which could be effective in prevention of elder abuse.

\section{OBJECTIVE}

The present study aimed to identify and describe psychoemotional consequences of hospitalized elder abuse from older patients' views.

\section{MATERIALS AND METHODS}

Research design: This exploratory qualitative study was conducted using inductive qualitative content analysis approach in order to determine the Psycho-emotional consequences of hospitalized elder abuse among older patients.

Participants and research context: In this study, 16 older patients in different wards of six educational hospitals affiliated to Shiraz University of Medical Sciences (internal, surgical and CCU) who had rich information about hospitalized elder abuse were recruited from October 2017 to September 2018. The participants were selected via purposive sampling and based on the informed judgment of the researcher, and also the need for variety in samples during the study. Data collection was continued until achieving data saturation where no new codes or categories were obtained. Data saturation refers to obtaining repeated information confirming the previously collected data. At this stage, no new data is obtained in interviews to complete and richen to the categories developed throughout the research.

The older patients aging 60 years and above who have experienced elder abuse in hospital and going longer than three days since the patient's current admission in the hospital, and had proper physical, mental, and psychological conditions for taking part in interviews were entered into the research. The patients had to possess verbal expression and be able to provide rich information about the intended phenomenon. They also had to be willing to participate in the study and respond to questions. The exclusion criteria of the study were not being willing to take part in the interviews and developing a critical condition.

Data collection: Data were gathered via individual semistructured interviews, which are among the best techniques for collecting data regarding sensitive issues. The interviews began with a general question: "can you tell me what hospitalized elder abuse means to you" and the following more specific questions were asked including "Do you have any experience of being abused by healthcare providers during your hospitalization period? Please mention.", "How did you feel in that situation?", "What happened between you and the personnel?", "What were the consequences of that incident for you?", "Have you had similar experiences of being abused by nurses, physicians, and other healthcare personnel in hospital settings before? Please mention them.", "What were the consequences of that incident for you?", "In your opinion, what are the consequences of hospitalized elder abuse?" These questions were only designed as interview guides, which were given open and interpretive answers. In fact, the participants' responses directed the interviews. All interviews were conducted by the first author (Z.N.) in a private room in the ward where the participant was hospitalized. The interviews were continued depending on the participants' conditions and, if necessary, further interview sessions were arranged. Each interview lasted for around 45 minutes. It should be noted that one of the participants had two interviews. Thus, a total of 17 interviews were carried out.

Data analysis: The study data were analyzed using the inductive qualitative content analysis method proposed by Elo and Kyngas (2008), which contained three stages. The first stage, preparation, which involved immediate transcription of the interviews and reading the transcriptions several times with the purpose of immersion in the data. The second stage, organization, consisted of coding, creating code tables, classifying the related codes, categorizing similar groups, and abstracting the main meaning of generic categories to form the main categories. Finally, reporting the main categories constituted the last stage (15).

Data trustworthiness: In this study, credibility was achieved by prolonged engagement, selection of participants from different sexes and age groups and various lengths of hospital stay, time integration (investigation in different shifts), place triangulation (different wards and hospitals), and peer debriefing. Dependability and conformability were ascertained via audit chain, including accurate interview techniques, precise transcription, maintenance of research documents, precise direction of interviews for data collection, and peer debriefing. Data transferability was strengthened via thick description of the study results, rich presentation of the results together with participants' quotes, purposive sampling, data collection from a sufficient number of a variety of knowledgeable participants.

Ethical considerations: This study was approved by the Ethics Committee of Shiraz University of Medical Sciences (Code: IR.SUMS.REC.1396.S613). At first, the participants were informed about the objectives, procedures, and voluntary nature of the study. They were also reassured about the confidentiality and anonymity of their data as well as their right to withdraw from the study any time during the research. After all, they were required to sign written informed consent forms for taking part in the study. Additionally, the interviews were recorded after gaining permission from the participants.

\section{RESULTS}

The participants were 16 hospitalized older patients aging 60-83 years (Table 1). Data analysis revealed 29 subcategories, 8 generic categories, and 3 main categories (Table 2 ). The main categories were feeling of insecurity, aggression, and learned helplessness.

\section{Feeling of Insecurity}

This category composed of three generic categories, namely perceived mental concerns, mistrust of healthcare team, and treatment abandonment.

Most patients stated that they felt insecure because of their perceived concerns resulting from the treatment team's abuse or negligence, including worry and doubt about the accuracy of the taken therapeutic measures, worry about wrong diagnosis and unnecessary procedures, fear from medical mistakes during medical processes and procedures, Worry 
Table 1. Demographic and clinical characteristics of the participants

\begin{tabular}{|c|c|c|}
\hline \multicolumn{2}{|c|}{ Variable } & \multirow{2}{*}{$\begin{array}{c}\text { Elderly Patients } \\
9\end{array}$} \\
\hline \multirow{2}{*}{ Gender } & Male & \\
\hline & Female & 7 \\
\hline \multirow{3}{*}{ Ward } & Medical & 7 \\
\hline & Surgical & 8 \\
\hline & $\mathrm{CCU}$ & 1 \\
\hline \multirow{6}{*}{ Education level } & Illiterate & 2 \\
\hline & Elementary education & 4 \\
\hline & Secondary education & 4 \\
\hline & Diploma & 3 \\
\hline & Upper diploma & 2 \\
\hline & Bachelor & 1 \\
\hline \multirow{2}{*}{\multicolumn{2}{|c|}{ Age }} & Min:60, Max:83 \\
\hline & & Mean: $70.25 \pm 6.94$ \\
\hline \multicolumn{2}{|c|}{ length of stay } & Min:3, Max:24 \\
\hline \multicolumn{2}{|c|}{ in hospital(days) } & Mean:10.56 \pm 5.60 \\
\hline
\end{tabular}

Table 2. Main categories, generic categories, and subcategories

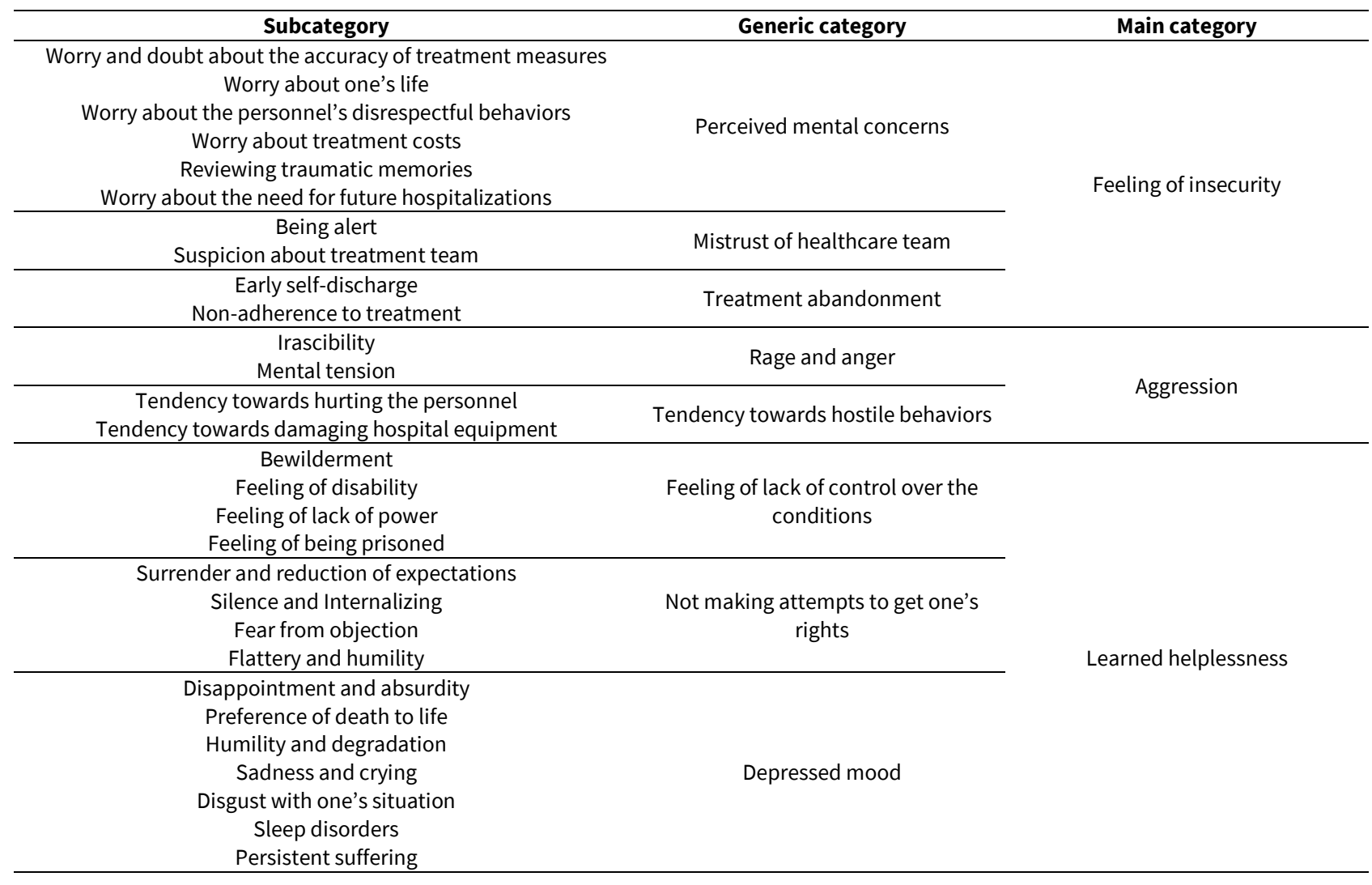

about one's life, fear from adverse events associated with surgical and invasive procedures performed by nursing and medical students, and worry about falling, hospital-acquired infections, or bedsore.

"I feel that my physician is doing a wrong treatment. S/he doesn't know what's wrong with me. S/he is doing the measures on the basis of my words. I may not know. I may have another disorder. They should do tests to diagnose my disease. S/he doesn't examine me. Only the students come for examination ..." (female patient, 60 years old).

"I didn't want to undergo treatment anymore. I felt bad. I just wanted to get out of the emergency department. I am a very patient person, but it was a hotchpotch. I felt they might make mistakes about me" (female patient, 63 years old).

The patients' feeling of insecurity also resulted from concerns about treatment expenditures due to long hospital- stay or expensive drugs, reviewing previous traumatic memories like returning to the past and remembering bitter memories of abuse and negligence during prior hospitalizations, worry about the personnel's disrespectful behaviors, reduction of their dignity, violation of their privacy, and suddenly and rude behaviors of personnel, and deep fear from future hospitalizations.

"I'm always stressful about experiencing previous problems, disrespects, and useless measures that wasted my time" (female patient, 63 years old).

"They prolonged my treatment process and I'm afraid of the costs at the end. I'm here for several days and the medications are being repeated again and again. I'm afraid of the costs. I will also have trouble getting rid of the complications. I should consume some medications again. They receive money for all these measures and the cost will be 
similar to that paid in private hospitals. I pay a lot of money and waste my time. Indeed, the long stay will break my spirits..." (male patient, 77 years old).

Another generic category of feeling of insecurity was the sense of distrust, including two subcategories: 1) being alert and remaining in the defensive mode and 2) pessimism towards the treatment team and getting disgusted with the hospital. In this regard, one of the participants maintained:

"One doesn't feel safe when coming to the hospital; a feeling of security that one is under treatment. I felt that they had abandoned me. If I don't follow things up, if I'm not careful, they do not care about me. I'm mentally disturbed. I am a tough person and I don't get disturbed easily, but I was really bothered here..." (female patient, 62 years old).

"When you are in the hospital, you should always be careful that nothing bad happens to you. I've experienced that you should never have complete trust in them; not in nurses, not in physicians. You should never be fooled by a doctor's name or fame..." (male patient, 68 years old).

Treatment abandonment was another dimension of feeling of insecurity, which was composed of two subcategories, namely early self-discharge from the hospital and nonadherence to treatment. In this respect, one of the participants stated:

"I said to myself that I'm ready to die in my own house but not to go to the hospital. I'm ready to suffer from pain, die, but not to go to the hospital. I don't want to continue my treatment. This is what I decided nine months after my operation..." (female patient, 60 years old).

"I suffered too much ... I wanted to discharge myself. I don't have a good economic status, but it doesn't matter. I sell what I have, but I save my life and will not get annoyed here..." (male patient, 72 years old).

\section{Aggression}

Aggression was a severe emotional response, which was shown by some elderly patients due to psychological tensions resulting from deprivation and irritability following the treatment team's abuse or negligence. This response was manifested through violence, anger, and irascibility towards the family members as well as the treatment team. Other features of aggression included tendency towards hostile behaviors with the treatment team, such as verbal and physical violence, or causing damage to hospital equipment in order to drain emotions and fears as well as to exert power, threat, and retaliation.

"I really got upset. I really wanted to die at that moment. I was so nervous, so angry that God knows I would take his/her life if I could. It affects one's spirits; someone insults you in front of others and you can't defend yourself..." (male patient, 77 years old).

"I had an argument with them last night. I wanted to throw it (the serum stand) at his/her face. They didn't give me my sleeping pills. They didn't change my foot's wound dressing and it was burning. I suffered both physically and mentally last night. They were talking and laughing at the station, but they didn't care about me. Then, the nurse came and asked why I had rung the alarm. Well, this alarm is here for patients. I really got upset. If $\mathrm{s} /$ he had said it again, I would have thrown it (the serum stand) at her face and it was not important at all; I said it to her, as well..." (male patient, 65 years old).
"I wanted to put the hospital on fire at that moment, because I felt lonely. I felt I had no support. I groaned too much, but it was not important for them at all..." (female patient, 63 years old).

\section{Learned Helplessness}

Due to the perceived abuse and negligence, some elderly patients believed that they could not control their conditions in the hospital and felt disabled, weak, powerless, and prisoned.

"Their maltreatments affect people, particularly older people. Older people are highly under pressure and feel that they are the weakest people in the world. They feel that they are so weak that someone insults them. They say they are so physically weak that a woman insults them and they can do nothing about it. They even wake up during the night..." (male patient, 77 years old).

"Their maltreatments affect people's spirits. An old person expects love from everyone, the youngest and oldest ones. When they are under pressure and in pain, they get tired, they want someone to look after them, they expect everything to go well. When they do not care, they would get upset, they cannot stand it, they think they are in a cage..." (female patient, 72 years old).

The participants who felt unable to control their conditions stopped making attempts to get their rights and tried to reduce their expectations. They kept silent against any abuse or inclined towards flattery and humility due to their dependence on the personnel, fear from being rejected, fear from the personnel's retaliation, and prevention of the treatment team from taking offense.

"I know they won't care. I've seen myself that some people in worse conditions raise objections. They say "what can we do? Are you our only clients? You drive us crazy. We will give you your records and you can go wherever you want". I've seen these. So, I say it's useless. What can I say? I have white hair (I'm old), but they don't respect me. They say something and I'll be upset for several days. I'll be humiliated. They want to shout, OK, let them do so without offense. We care, but they don't. They don't understand that we be trying to have patience ..." (male patient, 73 years old).

"I never objected. I felt miserable, I just cried. For example, why do I suffer from this pain? This person is watching you, $s /$ he has knowledge, $\mathrm{s} /$ he sees you are struggling with the disease. You want to be hopeful, but they do something that you lose hope completely..." (female patient, 76 years old).

Some elderly patients indicated that they had experienced the signs of depression, such as sadness, crying, disappointment, absurdity, preference of death to life, humility, shame, disgust with one's conditions, sleep disorders, and long-term suffering, due to their experienced abuse or negligence in the present or previous hospitalizations.

"I feel humiliated; something like shame, frustration. I don't know what to do, who to talk to. What should I do? ..." (male patient, 80 years old).

"I'll never forget that night. I may forget the pains, but I won't forget that suffer lasted from night to the next morning. Their behaviors caused me to feel the pain more. I have bad feelings when I remember that. I get broken spiritually..." (female patient, 62 years old). 
"I woke up during the night even days after that situation. I imagined it. I had a dream that I was fighting with the guard. It causes such mental pressure, it affects one's spirits..." (male patient, 77 years old).

"Well, these have negative mental effects. Such sufferings create a bitter memory for us and the memories will remain in our minds for years. I'll never forget that doctor's face..." (female patient, 63 years old).

\section{DISCUSSION}

Based on the study results, the Psycho-emotional consequences of hospitalized elderly abuse among hospitalized patients included three dimensions, namely feeling of insecurity, aggression, and learned helplessness.

Need for security is one of the most important human needs, and feeling of safety and security is associated with being free from physical threats and emotional injuries (16). Evidence has indicated the centrality of the feeling of security for hospitalized elderly patients (17) In this context, patients who feel safe and secure respond better to treatments, are discharged sooner, and will have lower treatment costs. A prior study revealed a relationship between gap in services and patients' feeling of safety (18). It seems that elderly people's lower health status together with inefficiency of the health system would enhance their feeling of insecurity (16). Healthcare insecurity has been defined as the feeling of uncertainty, anxiety, and vulnerability towards obtaining or maintaining sufficient healthcare services. This concept evaluates an individual's mental feeling of vulnerability, lack of control, and worry about getting healthcare services when needed (19).

Studies have shown that feeling of awareness, being recognized as a human being, and trust in the personnel's availability and efficiency for relieving patients' symptoms could facilitate the elderly patients' feeling of security. According to evidences, feeling of illness and pain could reduce patients' feeling of security. Therefore, healthcare providers must provide efficient medical and communicational support, including symptoms relief, in order to strengthen the patients' feeling of security (20). Additionally, the patients' feeling of security was influenced by coverage of all their needs, including the need for understanding, regaining control, being hopeful, and developing trust. In case these needs were not met, the patients felt insecure and their experiences ranged from turbulence and hopelessness to anxiety, struggle, and paranoid. For instance, the patients felt insecure in case they lost trust in the personnel (21). Perceptions of insecurity, in turn, affect individuals' subjective well-being, because insecurity is manifested through individuals' lack of control or autonomy in management of their surrounding environment. Perceptions of insecurity are also manifested through fear from losing control of one's life, one's properties, one's social relations, and even one's life (22). Moreover, insecurity beliefs with emotional origins are often accompanied with unpleasant feelings and hopelessness, and are normally labeled as feeling of insecurity (23). Insecure individuals feel that they are rejected and isolated, feel anxious and hostile, are pessimist and unhappy, and present the signs of tension and conflict. They are also more prone to selection of negative and incompatible responses, such as risk avoidance and overreaction (24).
In the present study, the participants mentioned aggression to be one of the main consequences of hospitalized elder abuse, which was manifested through severe rage and anger and tendency towards hostile behaviors. Anger has been defined as an experience of aggression, a syndrome of specific emotions and cognitions, and physiological reactions related to the tendency towards causing damage. Anger can involve mild mental emotions, such as irritability and annoyance, as well as severe emotions, such as extreme excitement and rage (25). On the other hand, aggression has been defined as hostile, traumatic, or destroying behaviors, particularly resulted from hopelessness (26). Aggression leads to physical or emotional damages to other individuals or destruction of properties, which involves obvious physical actions (fighting or breaking objects), verbal abuse (27), or threat to attack (28). Overall, anger is the emotional component and aggression is the behavioral component of irritability towards a negative emotional stimulant (29).

Unfortunately, aggression is quite common in acute care centers and can result in serious damages to the patient, personnel, other patients, and companions. Aggression may be caused by lack of control or respect. In this context, arousal due to the disease, environment, or communication problems with the personnel or the organization might result in strong emotions or cognitive or personality restrictions, which might be difficult to control. Aggression may also originate from emotions, such as fear, anxiety, grief, hopelessness, or anger, which are normally experienced by individuals or their close ones in the field of ill-health. External factors, such as the personnel's attitudes and behaviors, physical environment, and limitations, might cause aggression, as well. Overall, aggression represents the patients' distress or an attempt to meet the needs in individuals with excessive coping abilities (28). Older patients' aggression may cause great stress and provoke care providers to elder abuse of the patient (30). It seems that aggression may result in a vicious cycle for abuse in which hospitalized elder abuse results in older patients' aggression on one hand and older patients' aggression can lead to abuse toward them by caregivers on the other hand.

The current study findings indicated that learned helplessness was another important psycho-emotional outcome of hospitalized elder abuse, which might be experienced depending on the severity of abuse. Learned helplessness is a psycho-cognitive state in which individuals who cannot control a particular situation feel unable to exert logical control on other situations. Thus, they think that they cannot achieve their desired goals and stop making attempts. These individuals learn that they are helpless and, consequently, become depressed (31). Therefore, frustration and hopelessness occur due to considering the experienced outcome to be uncontrollable and unpredictable (32). Learned helplessness in older people may be caused by repetitive encounters with uncontrollable incidents, eventually resulting in cognitive, motivational, and emotional shortcomings (33). Evidence has indicated that learned helplessness, depression, fear, feeling of guilt, shame, and post-traumatic stress syndrome, which are caused by elder abuse, provide the ground for emotional distress (34). Studies have also demonstrated that in cases individual-centered care is missing and replaced with institution-centered care, resulting in routine care services, limited opportunity to take communication and psychological dimensions into account, lower time, and lower engagement with elderly patients, they 
adapt with and surrender to the situation, eventually leading to depression and emotionlessness (35).

Solomon (1990) mentioned three psychological factors for development of learned helplessness in healthcare centers, including healthcare providers' attitudes, interactions between healthcare providers and elderly patients, and injustice resulting from stereotypes. In that study, stereotypical behaviors towards older people were considered to play a major role in development of learned helplessness (36). Moreover, researchers have reported that increased number of hospitalizations and longer hospital stay could prone the patients to learned helplessness (32). This status may cost much for the elderly people and result in development of psychological pathologies with horrible consequences (36). Learned helplessness may also affect elderly people's cognitive performance, emotions, motivations, and self-esteem (37) and cause them to experience helplessness, anxiety, depression, lack of power, reduction of life satisfaction and ethics, and alienation (36).

Limitations and future research: One of the limitations of this study was the patients' fear from expressing the realities about elder abuse. In other words, worrying about not being provided with sufficient care services could disturb complete description of the consequences of hospitalized elder abuse. Moreover, since the participants were selected from various wards and hospitals, focus groups could not be formed to gain a richer understanding of hospitalized elder abuse consequences. This is recommended to be taken into consideration in future studies. Furthermore, this study was only conducted on the patients with complete cognitive ability. Therefore, further studies are suggested to investigate the consequences of elder abuse among the patients with cognitive disorders who are more vulnerable to abuse. Finally, the qualitative nature of the study might restrict the generalizability of the findings to other cultures and societies.

\section{CONCLUSION}

The findings of the present study indicated that hospitalized elder abuse could be accompanied with immediate Psycho-emotional consequences, such as feeling of insecurity and aggression, or serious and persistent consequences, such as learned helplessness. Thus, comprehensive investigations are recommended to be performed on each of these consequences so as to clarify and enrich the existing knowledge on the issue. Moreover, healthcare personnel must be aware of the consequences of their behaviors towards the elderly patients. In this regard, training the personnel and monitoring their performances are essential to prevent hospitalized elder abuse.

\section{ACKNOWLEDGEMENT}

This article was extracted from Zeinab Naderi's PhD dissertation financially supported by Shiraz University of Medical Sciences. Hereby, the authors would like to thank the hospitals' managers and hospitalized elderly patients who cooperated in the research.

\section{Funding}

This work was supported by the Research Vice-Chancellor of Shiraz University of Medical Sciences (grant No. 1396-01-0814139).

\section{Declaration of Conflicting Interests}

The authors declare no potential conflict of interests with respect to the research, authorship, and/or publication of this article.

\section{REFERENCES}

1. Yon Y, Ramiro-Gonzalez M, Mikton CR, et al. The prevalence of elder abuse in institutional settings: a systematic review and meta-analysis. Eur J Public Health 2018:1-10. https://doi.org/10.1093/eurpub/cky093 PMid:29878101 PMCid:PMC6359898

2. Perel-Levin S. Discussing screening for elder abuse at primary health care level. World Health Organization 2008.

3. Ziminski CE and Phillips LR. The Nursing Role in Reporting Elder Abuse: Specific Examples and Interventions. Journal of gerontological nursing 2011;37:19-23. https://doi.org/ 10.3928/00989134-20111010-01 PMid:22007618

4. Pillemer K, Burnes D, Riffin C, et al. Elder abuse: global situation, risk factors, and prevention strategies. The Gerontologist 2016;56:194-205. https://doi.org/10.1093/ geront/gnw004 PMid:26994260 PMCid:PMC5291158

5. Glendenning F. Elder abuse and neglect in residential settings: the need for inclusiveness in elder abuse research. Journal of Elder Abuse \& Neglect 1999;10:1-11. https://doi.org/10.1300/J084v10n01_01

6. Wijma B, Zbikowski A Brüggemann AJ. Silence, shame and abuse in health care: theoretical development on basis of an intervention project among staff. BMC medical education 2016;16:75. https://doi.org/10.1186/s12909-0160595-3 PMid:26922381 PMCid:PMC4769844

7. Rytterström $P$, Arman M, Unosson M. Aspects of care culture in municipal care for elderly people: a hermeneutic documentary analysis of reports of abuse. Scandinavian journal of caring sciences 2013;27:354-62. https://doi.org/ 10.1111/j.1471-6712.2012.01042.x PMid:22846105

8. Lothian K, Philp I. Care of older people: Maintaining the dignity and autonomy of older people in the healthcare setting. BMJ: British Medical Journal 2001;322:668. https://doi.org/10.1136/bmj.322.7287.668 PMid:11250856 PMCid:PMC1119851

9. Khalili Z, Taghadosi M, Gilasi H, Sadrollahi A. The prevalence of elder abuse and associated factors among the elderly in Kashan city, Iran. Journal of Basic Research in Medical Sciences 2016;3:26-34. https://doi.org/10.18869/ acadpub.jbrms.3.2.26

10. Krug EG, Dahlberg LL, Mercy JA, et al. The world report on violence and health. Geneva, World Health Organization 2002. https://doi.org/10.1016/S0140-6736(02)11133-0

11. Swahnberg K, Wijma B. Staff's perception of abuse in healthcare: a Swedish qualitative study. BMJ open 2012;2:e001111. https://doi.org/10.1136/bmjopen-2012001111 PMid:23015598 PMCid:PMC3467650 
12. Berglund M, Westin L, Svanström R, et al. Suffering caused by care-Patients' experiences from hospital settings. International journal of qualitative studies on health and well-being 2012;7. https://doi.org/10.3402/qhw.v7i0.18688 PMid:22943888 PMCid:PMC3430007

13. Brüggemann AJ, Wijma B, Swahnberg K. Abuse in health care: a concept analysis. Scandinavian journal of caring sciences 2012;26:123-32. https://doi.org/10.1111/j.14716712.2011.00918.x PMid:21883345

14. Brüggemann AJ, Wijma B, Swahnberg K. Patients' silence following healthcare staff's ethical transgressions. Nursing ethics 2012;19:750-63. https://doi.org/10.1177/ 0969733011423294 PMid:22547488

15. Elo $S$, Kyngäs $H$. The qualitative content analysis process. Journal of advanced nursing 2008;62:107-15. https://doi.org/10.1111/j.1365-2648.2007.04569.x PMid:18352969

16. Fagerström L, Gustafson Y, Jakobsson G, et al. Sense of security among people aged 65 and 75: external and inner sources of security. Journal of advanced nursing 2011;67:1305-16. https://doi.org/10.1111/j.1365-2648.2010 .05562.x PMid:21231954

17. Hung L, Phinney A, Chaudhury $H$, et al. "Little things matter!" Exploring the perspectives of patients with dementia about the hospital environment. International journal of older people nursing 2017;12:e12153. https://doi.org/10.1111/opn.12153 PMid:28418180 PMCid:PMC5574000

18. Rostami F, Nadi A, Abedi G, et al. Relationship between the patients' sense of security and the gap in the quality of services in hospitals of Sari city, Iran. Cukurova Med J 2018;43(4):958-66. https://doi.org/10.17826/cumj.399915

19. Tomsik PE, Smith S, Mason MJ, et al. Understanding and Measuring Health Care Insecurity. Journal of health care for the poor and underserved 2014;25:1821. https://doi.org/10.1353/hpu.2014.0180 PMid:25418245 PMCid:PMC4492521

20. Krevers B, Milberg A. The instrument 'Sense of Security in Care - Patients' Evaluation': its development and presentation. Psycho - Oncology 2014;23:914-20. https://doi.org/10.1002/pon.3502 PMid:24677414

21. Hupcey JE. Feeling safe: the psychosocial needs of ICU patients. Journal of Nursing Scholarship 2000;32:361-7. https://doi.org/10.1111/j.1547-5069.2000.00361.x PMid:11140200

22. Wills-Herrera E, Orozco LE, Forero-Pineda C, et al. The relationship between perceptions of insecurity, social capital and subjective well-being: Empirical evidences from areas of rural conflict in Colombia. The Journal of SocioEconomics 2011;40:88-96. https://doi.org/10.1016/j.socec. 2010.08.002

23. Bar - Tal D, Jacobson D. A psychological perspective on security. Applied Psychology 1998;47:59-71. https://doi.org/10.1111/j.1464-0597.1998.tb00013.x

24. Alegre A. Emotional Security and its relationship with emotional intelligence. Virginia Polytechnic Institute and State University, 2008.
25. Berkowitz L, Harmon-Jones E. Toward an understanding of the determinants of anger. Emotion 2004;4:107. https://doi.org/10.1037/1528-3542.4.2.107 PMid:15222847

26. Bo S, Abu-Akel A, Kongerslev M. Metacognition as a Framework to Understanding the Occurrence of Aggression and Violence in Patients with Schizophrenia. Social cognition and metacognition in schizophrenia: Psychopathology and treatment approaches, Chapter: 8, Publisher: Academic Press, Editors: Paul H. Lysaker, Martin Brune, Giancarlo Dimaggio, 2014:137-45. https://doi.org/10.1016/B978-0-12-405172-0.00008-9 PMid:24838067 PMCid:PMC4411345

27. Barratt ES. Agonistic Behavior. International Encyclopedia of the Social \& Behavioral Sciences 2001. https://doi.org/10.1016/B0-08-043076-7/03576-2

28. Harwood R. How to deal with violent and aggressive patients in acute medical settings. The journal of the Royal College of Physicians of Edinburgh 2017;47:94-101. https://doi.org/10.4997/JRCPE.2017.218 PMid:28675195

29. Leibenluft E, Stoddard J. The developmental psychopathology of irritability. Development and psychopathology 2013;25:1473-87. https://doi.org/10.1017 /S0954579413000722 PMid:24342851 PMCid:PMC4476313

30. Jackson JL, Mallory R. Aggression and violence among elderly patients, a growing health problem. Journal of General Internal Medicine 2009;24:1167. https://doi.org/10.1007/s11606-009-1099-1 PMid:19730956 PMCid:PMC2745572

31. Flannery RB Jr. Treating learned helplessness in the elderly dementia patient: preliminary inquiry. American Journal of Alzheimer's Disease \& Other Dementias 2002;17:345-9. https://doi.org/10.1177/153331750201700605 PMid:12501481

32. Smallheer BA. Learned helplessness and depressive symptoms in patients following acute myocardial infarction. Doctoral Dissertation, Faculty of the Graduate School of Vanderbilt Univ., Nashville, Tennessee, 2011.

33. Nuvvula S. Learned helplessness. Contemporary clinical dentistry 2016;7:426. https://doi.org/10.4103/0976237X.194124 PMid:27994405 PMCid:PMC5141652

34. National Research Council. Elder mistreatment: Abuse, neglect, and exploitation in an aging America. National Academies Press (NAP); 2003 Feb 6.

35. James I, Ardeman-Merten R and Kihlgren A. Ontological security in nursing homes for older persons-personcentred care is the power of balance. The open nursing journal 2014;8:79. https://doi.org/10.2174/1874434601408 010079 PMid:25852785 PMCid:PMC4382558

36. Solomon K. Learned helplessness in the elderly: Theoretic and clinical considerations. Occupational Therapy in Mental Health 1990;10:31-51. https://doi.org/10.1300/ J004v10n03_02

37. Priddy JM, Teitelman JL, Kivlighan DM, et al. Overcoming learned helplessness in elderly clients: Skills training for service providers. Educational Gerontology: An International Quarterly 1982;8:507-18. https://doi.org/10.1080/0360127820080509 